\title{
Relative Warp Analysis of the Pronotum Shape Variability among Twelve Selected Populations of the Coconut Leaf Beetle, Brontispa longissima Found in the Mindanao Island
}

\author{
Kris A. Ortizo and Cesar G. Demayo
}

\begin{abstract}
The aim of the study was to determine the pronotum shape variability of the coconut leaf beetle, Brontispa longissima and to identify the shape discontinuity using relative warp analysis. Samples were taken from twelve sampling site under eight provinces in Mindanao. Using the results from the relative warp analysis, histograms, CVA and box plot were generated to visualize variation distribution. Cluster analysis was used to determine the degree of variation between pronotum shape and within populations, with the Kruskal-Wallis test used to determine the significance of difference. Results of the relative warp (RW) analysis showed six general and significant descriptions of pronotum shape. CVA scatter plots showed intrapopulation variation in pronotum shape but Kruskal-Wallis test showed significant differences in several populations. Cluster analysis resulted in the formation of two subclusters in each grouping. The observed morphological disparity among the selected Brontispa populations suggested possible morphological divergence between and within populations. It was concluded that there is a significant relationship in the pronotum shape of $B$. longissima with regard to its shape variation.
\end{abstract}

Index Terms-Coconut leaf beetle, geometric morphometrics, landmarks, pronotum, relative warp analysis.

\section{INTRODUCTION}

The coconut hispine beetle Brontispa longissima Gestro (Coleoptera: Chrysomelidae) is one of the most damaging insect pests of coconuts and other ornamental palm species. Both larvae and adults of the beetle feed on the abaxial and adaxial epidermis tissues of developing unopened leaves of trees, destroying the growing points of the leaves. The rasping of the pest would cause longitudinal necrotic patches on the young leaves, thus injuring coconut seedlings and infesting the severely damaged parts. This beetle can cause significant production losses, and high infestation level may results in the tree's death [1]-[4].

Invasive pest species are a major cause and consequence of human-mediated global change and hence, one of the major challenges facing human agriculture and biodiversity conservation. The nature of founding events of invasions can be a vital determinant of their long-term success and impact, which is why they are generally intensely studied, often leading to important management decisions [5]. Studies on the extent of variability of invasive species are very important as these organisms contribute in the continuing decline in biodiversity as well as compete with man as most pests and weeds of agricultural systems do [6]. Correctly identified pest species allow for immediate control and management efforts without wasting valuable resources, placing the discipline of taxonomy at the forefront of invasive species research, but accurate identification of a new pest is not always easy. Many introduced insects belong to species complexes that contain many morphologically similar cryptic species. Subsequently, proper identification can be limited by a lack of taxonomic resources (modern keys), distinctive morphological characteristics, or even a muddled taxonomic history.

With the advances in statistics, geometry and biology, analysis of shapes have become more quantitatively described, leading to the development of geometric morphometrics (GM), a statistical analysis of shape that made possible for the fast and reliable way of studying biological forms [4]. Currently, there are several arrays of GM methods, the major difference among them being in the manner of capturing shape data and in modeling the morphologies for multivariate analysis. Among these methods include the elliptic Fourier analysis for describing outline shapes and the landmark-based morphological variation via recording the landmark coordinates or points that are assumed to be homologous to one organism to another [6], [7].

There have been only a handful of studies conducted on the coconut leaf beetle, including host plant suitability [8], laboratory rearing [9], biological and chemical control [2], [10], [11], agricultural assessment [12] and even molecular microsatellite analysis [13]. Yet so far, no studies regarding shape variability of the population structure and its phylogenetic relationship have been made on the insect pest. To date, little is known on the population structure in the shapes of the pronotum of $B$. longissima. Thus, this study aimed to determine the phenotypic shape variability of selected $B$. longissima populations in the Mindanao Island and to identify the shape discontinuity or differences using landmark-based geometric methods of relative warp analysis. This study also aimed to explore how shape variability possibly determines phylogenetic relationship between and within populations of $B$. longissima.

\section{MATERIALS AND METHODS}

was supported in March 3, 2014; revised May 25, 2014. This work Technology-Accelerated Science and Technology Human Resource Department Program (DOST-ASTHRDP).

The authors are with the Department of Biological Sciences, CSM, MSU-IIT, Iligan City, Philippines (e-mail: kris.ortizo@gmail.com, cgdemayo@gmail.com). 
localities of Brontispa infestation under eight different porvinces in Mindanao, namely: Zamboanga Del Norte (Sibutad), Zamboanga Del Sur (Pagadian City and Aurora), Zamboanga Sibugay (Malangas), Misamis Occidental (Aloran), Lanao Del Norte (Pantao Ragat), Lanao Del Sur (Bayang, Bubong, Marawi City, and Wao), Bukidnon (Musuan), and Agusan Del Norte (Fig. 1).

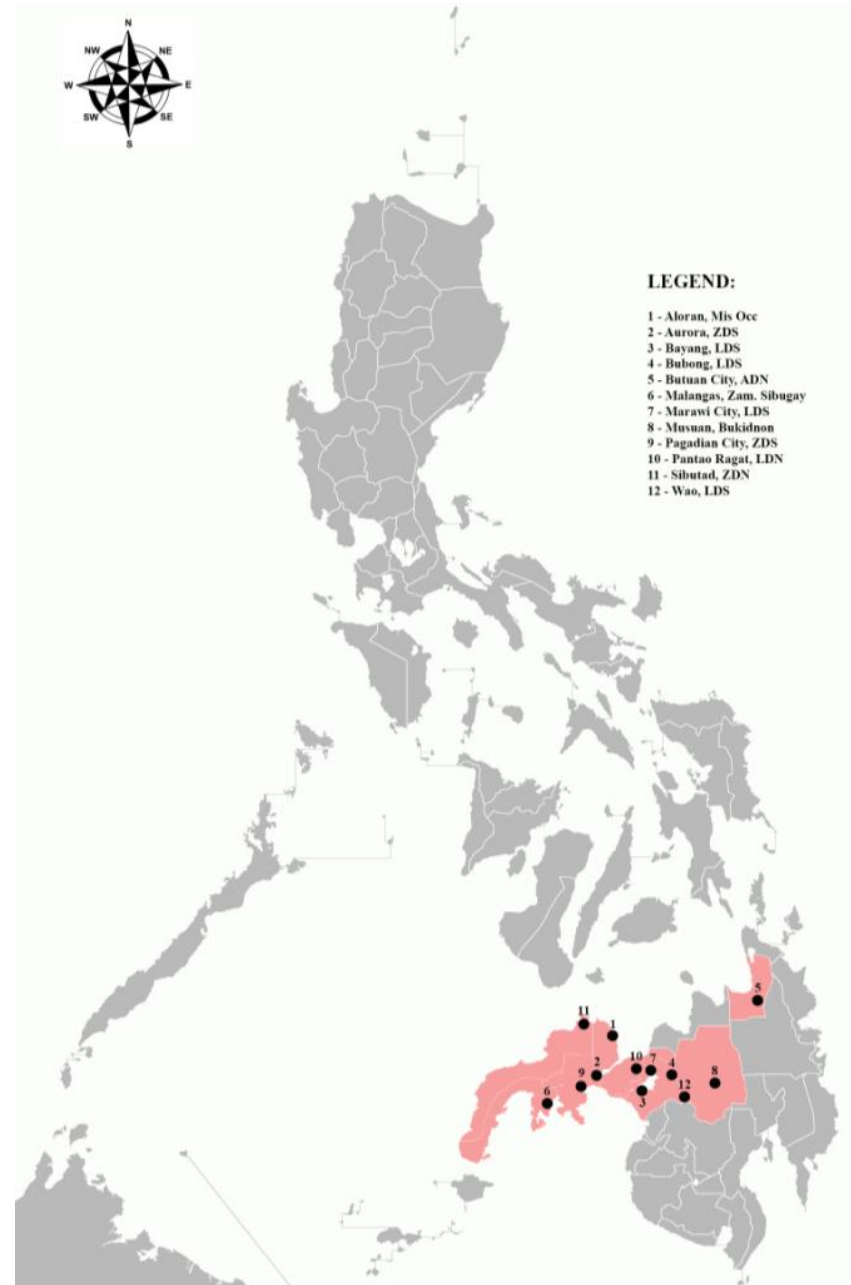

Fig. 1. Map of the Philippines showing the eight different provinces (colored red) where the twelve sampling sites (black dots) are located.

A total of 720 individuals $(M=360 ; F=360)$ were pooled from the sampling sites. Collected samples were placed in containers containing fixative solution composed of $70 \%$ ethanol and $30 \%$ glacial acetic acid for preservation. Samples were then placed individually in eppendorf tubes containing 3-5 drops of the fixative solution. Males were distinguished from female species based on the extra tergite found in the ventral side of the abdominal apices of the first (Fig. 2).
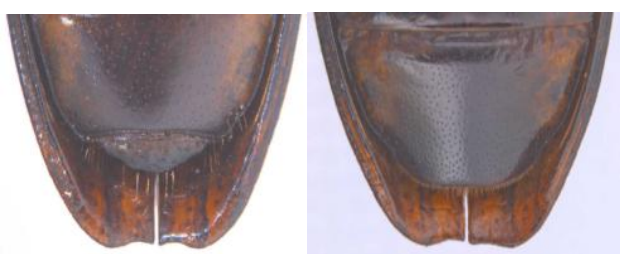

Fig. 2. Male abdominal apices (left) showing the extra tergite and the female abdominal apices (right).

\section{B. Sample Imaging, Organizing and Digitizing}

Pronotum images were taken by using an advanced USB
Digital Microscope mounted on a small tripod to ensure fixed and uniform distance in the image acquisition. Images of the samples were immediately transferred and saved into the laptop where the USB research microscope was attached to. The samples were placed in a way that the viewpoint of the microscope was $90^{\circ}$ to the midpoint of the pronotum. Image triplication was later done to ensure stability. Images were then categorized according to their sampling location and their sex. Images were then digitized by using tpsUtil software [14] and then saved as thin-plate spline (TPS) files.

\section{Landmark Selection and Landmarking}

A total of 32 landmarks consisting of 22 anatomical landmarks as well as 10 pseudo-landmarks were assigned to the distinct features of the pronotum of B. longissima. In landmark-based morphometric analyses, the morphology of an object is represented by sets of coordinates of landmarks points, where landmarks are chosen due to their ease of identification, their homology and ability to capture the general shape of each morphological structure. The landmark data will provide some information such as the orientation, rotation and scale of the specimen [15]. The landmark characters used in the analyses of the pronotum were chosen due to the differences in terms of symmetry and orientations were found to be often seen and noted under the microscope. A summary of the landmarks used in this study is shown in Fig. 3. Table I shows the description of the chosen landmarks. The anatomical landmarks include LM 1, 3, 4, 8, and 13 while pseudo-landmarks include LM 2, 5, and 9.

The software tpsDig2.12 [16] was then used to acquire the landmark points from the digitized images so as to acquire the " $x$ " and " $y$ " Cartesian coordinates of the landmarks. The same landmark coordinates generated by the software were also used in acquiring the sliders and links data to enhance specimen images.

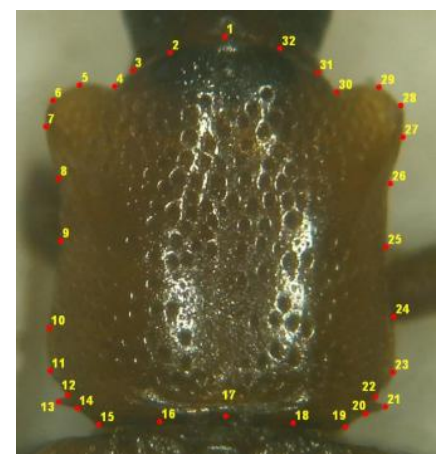

Fig. 3. Image of Brontispa longissima pronotum showing the designated landmarks and pseudolandmarks.

\section{Landmark-Based Analysis and Statistical Analysis}

The software tpsRelW [17] was for relative warp analysis to acquire information on shape variability, which includes relative warp scores, consensus shape, and centroid size. The same software was also used to align raw coordinate data prior to analysis so as to remove size and arbitrary positioning effects of the specimens relative to the reference axis [15], [18].

Using the result gathered from the relative warp analysis, histograms and box-and-whiskers-plots were generated by using the PAST software [19]. The first and second relative 
warp scores, considered to be the most informative, were then subjected to Canonical Variance Analysis (CVA), Kruskal-Wallis Test, and Cluster Analysis by using the same software. CVA, together with the histograms and box plots, were used to visualize data distribution over variable ranges. Kruskal-Wallis Test, a non-parametric test used to compare independent sample data groups, used the first and second relative warp scores of the pooled all-female, all-male, and combined populations to determine the level of significant difference among the pronotum shape. To determine the degree of variation between pronotum shapes and within sexes and populations, cluster analysis was used by using the centroid size of the pooled data [20]. All statistical analyses used 0.05 level of significance.

TABLE I: DESCRIPTION OF THE ANATOMICAL LANDMARK POINTS OF THE BRONTISPA LONGISSIMA PRONOTUM

\begin{tabular}{|c|c|}
\hline $\begin{array}{c}\text { LANDMARK } \\
\text { NO. }\end{array}$ & DESCRIPTION OF LANDMARK POINTS \\
\hline 1 & First LM in the tip of the anterior part of the pronotum \\
\hline 2 & LM in the anterior margin of the pronotum between LM 1 and LM3 \\
\hline 3 & LM in the left juncture of the head and the pronotum \\
\hline 4 & LM in the diverging point between the mid-anterior and the left upper curve (i.e. anterolateral side) of the pronotum \\
\hline 5 & LM in the left anterolateral margin of the pronotum between LM 4 and LM 6 \\
\hline 6 & LM in the tip of the left upper curve of the pronotum \\
\hline 7 & LM in the left anterolateral margin of the pronotum between LM 6 and LM 8 \\
\hline 8 & LM in the curving point between the left anterolateral margin and the left lateral margin \\
\hline 9 & LM in the left lateral margin between LM 8 and LM 10 \\
\hline 10 & LM in the curving point between the left lateral margin and the left posterolateral side of the pronotum \\
\hline 11 & LM in the curving point between LM 10 and LM 12 \\
\hline 12 & LM in the anterior base of tip of the left posterolateral side of the pronotum \\
\hline 13 & LM in the tip of the left posterolateral side of the pronotum \\
\hline 14 & LM in the posterior base of tip of the left posterolateral side of the pronotum \\
\hline 15 & LM in the diverging point between the left posterolateral margin and the mid-posterior margin of the pronotum \\
\hline 16 & LM in the posterolateral margin of the pronotum between LM 15 and LM 17 \\
\hline 17 & LM in the tmiddle of the posterior part of the pronotum \\
\hline 18 & LM in the posterolateral margin of the pronotum between LM 17 and LM 19 \\
\hline 19 & $\mathrm{Lm}$ in the diverging point between the right lateral margin and the mid-posterior margin of the pronotum \\
\hline 20 & LM in the posterior base of tip of the right posterolateral side of the pronotum parallel to LM 14 \\
\hline 21 & LM in the tip of the right posterolateral side of the pronotum \\
\hline 22 & LM in the anterior base of tip of the right posterolateral side of the pronotum parallel to LM 12 \\
\hline 23 & LM in the curving point between LM 22 and LM 24 \\
\hline 24 & LM in the curving pointbetween the right lateral margin and the right posterolateral side of the pronotum parallel to LM 10 \\
\hline 25 & LM in the right anterolateral margin of the pronotum between LM 24 and LM 26 \\
\hline 26 & LM in the curving point between the right anterolateral margin and the right lateral margin parallel to LM8 \\
\hline 27 & $\mathrm{LM}$ in the right anterolateral margin of the pronotum parallel to LM 7 \\
\hline 28 & LM in the tip of the right upper curve of the pronotum parallel to LM6 \\
\hline 29 & $\mathrm{LM}$ in the right anterolateral margin parallel to LM 5 \\
\hline 30 & LM in the diverging point between right upper curve and the mid-anterior of the pronotum parallel to LM4 \\
\hline 31 & $\mathrm{LM}$ in the right juncture of the head and the pronotum parallel to LM 3 \\
\hline 32 & LM in the anterior margin of the pronotum between LM 31 and LM 1 \\
\hline
\end{tabular}

\section{RESULTS AND DISCUSSION}

Results of the relative warp analysis generated six pronotum shape descriptions which are different between and within sexes and location: in the all-female population, the six pronotum shape descriptions are the following: reduced anterolateral portion with a more pronounced posterolateral side; blunter anterior margin with a near linear lateral sides; slightly wider pronotum width towards the posterolateral sides; wider pronotum width with a curvier and more pronounced right lateral margin; a curvier and more pronounced left lateral margin; and a more pronounced anterolateral portion with a very blunt posterior margin. In the all-male populations, the six pronotum shape descriptions are the following: a wider pronotum width with a more pronounced anterior portion and a concaved posterior portion; a more pronounced mid-anterior portion with a reduced and less pronounced anterolateral sides; a slightly wider pronotum width towards the posterolateral portions and a curvier lateral margins; a near-linear lateral margins with a less pronounced anterolateral margins; a wider pronotum width towards the anterolateral portions with a blunter anterior margin; and a curvier lateral margins with a concaved posterior portion. In the combined populations, the six pronotum shape descriptions are the following: a wider pronotum width with a more pronounced anterolateral and posterolateral portions and a concaved posterior margin; a near-linear lateral margins with a blunter anterior and posterior portions; a slightly wider pronotum width towards the posterolateral portion and curvier lateral sides; a more pronounced and curvier right lateral margin; a blunter anterior margin with a slightly curved lateral sides; and a curvier left lateral margin with a slightly pronounced left posterolateral portion (Fig. 4). Variation descriptions of the pronotum shape are presented in Table II. The first relative warp (RW1) explains that majority of the individuals in a population falls under a pronotum shape that is, more pronounced or blunter on one or both portion. Thus, pronotum may either have a more pronounced anterior portion but blunter posterior side or vice versa, or pronotum may either be more pronounced in both anterior and posterior portion or vice versa. The second relative warp (RW2) explains the slight variation in the anterolateral portion of the pronotum, which may either be slightly pronounced or slight blunt. The third relative warp (RW3) describes variation in the lateral sides, which may either be slightly wider and curvier or near-linear and 
narrower. The fourth relative warp (RW4) describes variation in one of the lateral sides to appear more pronounced or curvier compared to the other lateral side. The fifth relative warp (RW5) describes the variation in the pronotum width towards the anterolateral portion, which may be slightly wider but blunter or narrower but more pronounced. The last relative warp (RW6) describes the variation in the posterolateral margin, which may either be concaved or convex in shape.

TABLE II: VARIABILITY IN THE PRONOTUM SHAPE OF B. LONGISSIMA BASED ON THE SignifiCANT RELATIVE WARP SCORES

\begin{tabular}{cl}
\hline RW & \multicolumn{1}{c}{ All-Female Population } \\
\hline & \\
& - Variation in the anterolateral portion of the pronotum: reduced but more \\
& concaved in (-) than in $(+)$ \\
$1 \quad$ & - Variation in the posterolateral portion of the pronotum: more \\
& pronounced in (-) than in (+) \\
& - Variation in the posterior margin of the pronotum: more convex in $(+)$ \\
& more concave in $(-)$
\end{tabular}

All-Male Population

- Variation in pronotum width: wider in (-) than in (+)

- Variation in the anterolateral portion of the pronotum: reduced but more pronounced in (-) than in (+)

- Variation in the anterior margin of the pronotum: more pronounced in (-) than in (+)

- Variation in the posterior margin of the pronotum: convex in $(+)$, concave in (-)

- Variation in the anterior base tip of the posterolateral portion of the pronotum: wider base tip angle in (+) than in (-)

- Variation in the anterior margin of the pronotum: more pronounced in (-) than in (+)

- Variation in the anterior portion of the pronotum: more blunt in $(+)$ than in (-)

2 - Variation in the anterior base tip of the posterolateral sides of the pronotum: more pronounced in (+) than in (-)

- Variation in the right anterolateral portion of the pronotum: more pronounced in (-) than in (+)

- Variation in the anterolateral portion of the pronotum: reduced but more pronounced in (-) than in (+)

- Variation in the lateral sides of the pronotum: slightly curved in (-) than in (+)

- Variation in the posterior margin of the pronotum: slightly concave in

$(-)$ than in (+)

- Variation in the anterior base tip of the posterolateral portion of the pronotum: wider base tip angle in (-) than in (+)

- Variation in pronotum width: slightly wider in (-) than in (+)

- Variation in the pronotum width: wider in (+) than in (-)

- Variation in the posterolateral sides of the pronotum: more pronounced in (-) than in (+)

3 - Variation in the posterior margin of the pronotum: more concaved in (-) than in (+)

- Variation in the anterolateral portion of the pronotum: left anterolateral side more pronounced in (-), right posterolateral side more pronounced in $(+)$

- Variation in pronotum length: slightly longer in (+) than in (-)

- Variation in pronotum width: slightly wider in

(-) than in (+)

- Variation in the anterolateral portion of the pronotum: right

4 anterolateral side more pronounced and slightly enlarged in (-) than in $(+)$

- Variation in anterior margin of the pronotum: more blunt in (-) than in $(+)$

- Variation in the anterior base tip of the posterolateral portions of the pronotum: wider base tip angle in(-) than in (+)

- Variation in anterolateral portion of the pronotum: enlarged and more pronounced left anterolateral side in $(+)$, more blunt in the right anterolateral side in $(+)$

- Variation in the lateral sides of the pronotum: more curved towards the posterolateral portion in (+) than in (-)

- Variation in the anterior base tip in the posterolateral portion of the pronotum: wider base tip angle in (+) than in (-)

- Variation in pronotum width: slightly wider in (+) than in (-)

- Variation in the anterior margin of the pronotum: more blunt in (+) than in (-)

- Variation in the anterolateral portion of the pronotum: enlarged and more pronounced left anterolateral side in (-), enlarged and more pronounced right anterolateral side in $(+)$

- Variation in the lateral sides of the pronotum: more curved in (-) than in $(+)$

- Variation in the posterolateral portion of the pronotum: more pronounced in (+) than in (-)

- Variation in the right anterolateral portion of the pronotum: more pronounced and slightly enlarged in $(+)$ than in (-)

- Variation in the left lateral side of the pronotum: enlarged and more pronounced towards the curving point between the left lateral side and the posterolateral portion in (-).

5 - Variation in the anterior base tip of the posterolateral portion of the pronotum: wider base tip in the left posterolateral side in $(+)$, wider base tip in the right posterolateral side in (-)

- Variation in the right anterolateral portion of the pronotum: slightly enlarged and more pronounced in (+) than in (-)

- Variation in the anterior portion of the pronotum: more pronounced in

(+) than in (-)

- Variation in the anterolateral portion of the pronotum: enlarged and

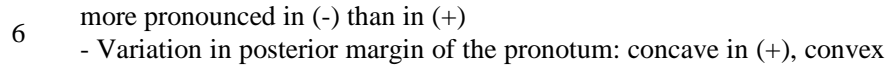
in (-)

- Variation in the anterior base tip of the posterolateral portion of the pronotum: wider base tip angle in $(+)$ than in $(-)$

- Variation in the anterior margin of the pronotum: more pronounced in (-) than in (+)

- Variation in the anterolateral portion of the pronotum: reduced, more blunt, but wider in (-) than in (+)

- Variation in the posterior margin of the pronotum: slightly convex in $(+)$, concaved in $(-)$

- Variation in the posterolateral portion of the pronotum: wider anterior base tip angle and more pronounced posterior tip in (-) than in (+)

- Variation in the anterior margin of the pronotum: more pronounced in $(-)$ than in (+)

- Variation in the right anterolateral side of the pronotum: more pronounced and slightly enlarged in $(+)$ than in (-)

- Variation in the left lateral margin: more curved and slightly pronounced towards the posterolateral portion in (-) than in (+)

- Variation in the posterior margin of the pronotum: slightly convex in $(+)$, concaved in $(-)$

- Variation in the anterior base tip of the posterolateral portion of the pronotum: wider left anterior base tip angle in $(+)$, wider right anterior base tip angle in (-)

RW Combined Population

- Variation in the anterior margin of the pronotum: more pronounced in (+), very blunt in (-)

- Variation in anterolateral portion of the pronotum: reduced but more pronounced in $(+)$

- Variation in pronotum width: wider length in (+) than in (-)

1 - Variation in the lateral sides of the pronotum: more curved in $(+)$ than in $(-)$

- Variation in the posterolateral portion of the pronotum: enlarged but less pronounced posterolateral tip in (+) than in (-)

- Variation in the posterior margin of the pronotum: concaved in (+), convex in (-) 


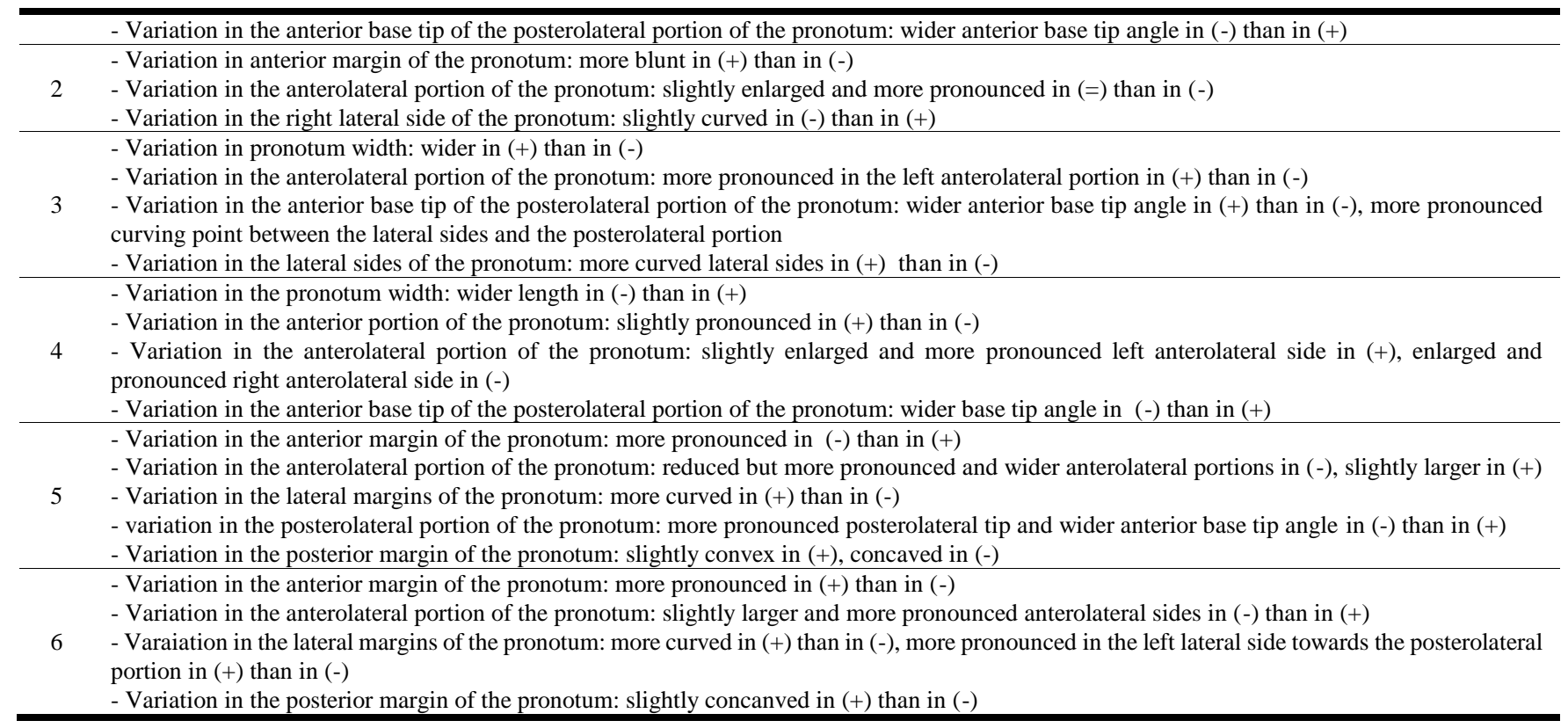

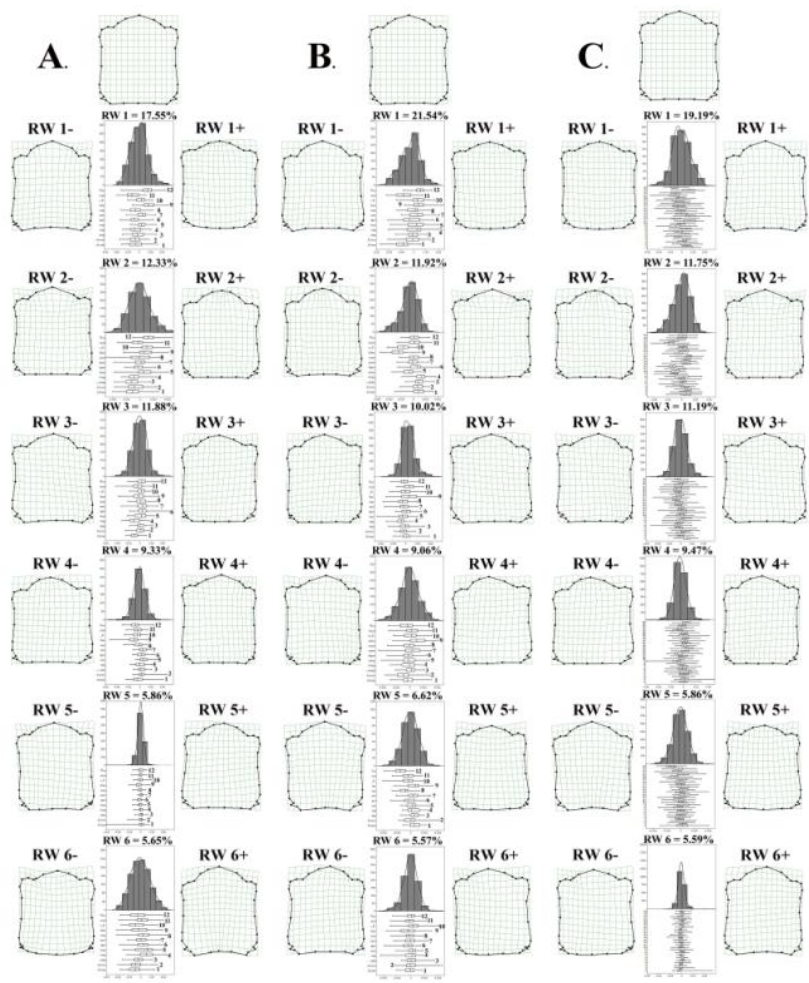

Fig. 4. Summary of the landmark-based geometric morphometric analysis showing the consensus morphology and variationin pronotum shapes of $B$. longissima explained by each significant relative warp. A. All-female only. B. All-males only. C. Combined populations.

Cluster analysis of the centroid size of the all-female and all-male populations showed the clustering of different populations into two groups (Fig. 6 and Fig. 7). In the all-female populations, the first cluster comprised the populations from Aloran, Aurora, Pantao Ragat, and Wao, all of which are located in provinces that are adjacent with each other. In this cluster, significant difference was achieved in population level, although the formation of this cluster may suggest that the populations may be derived from common subspecies or may share a common trait with one another. In the second cluster, which comprises the rest of the all-female populations, the pronotum shape patterns from the Bayang, Malangas, Marawi and Sibutad populations were shown to be not significantly different from each other. In the all-male populations, the Aurora, Bayang and Malangas populations were not significantly different from one another. The Sibutad population appeared to be distinct from the other populations in the remaining cluster.

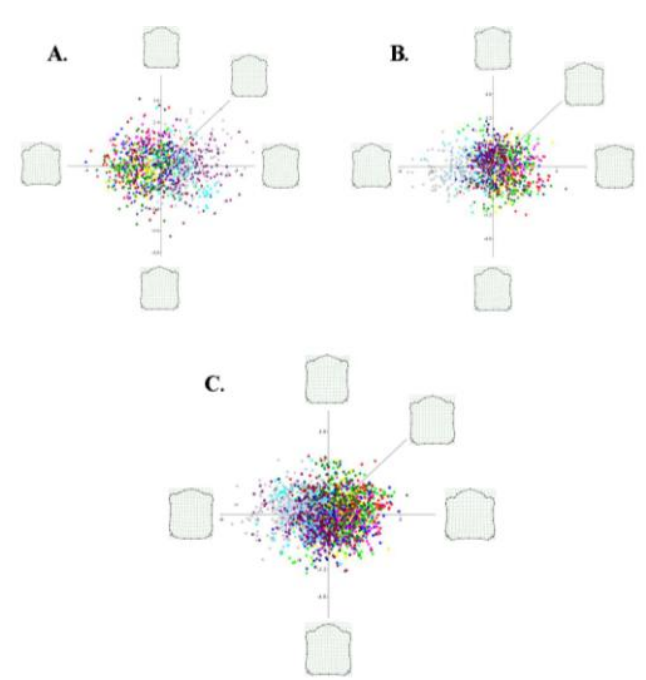

Legend: Aloran (Red), Aurora (Blue), Bayang (Pink), Bubong (Light Green), Butuan City (Blue-Green), Malangas (Yellow), Marawi City (Dark Blue), Musuan (Maroon), Pagadian City (Gray), Pantao Ragat (Sky Blue) Sibutad (Dark Green) and Wao (Violet).

Fig. 5. Scatter Plot of the canonical axes showing significant differences in the pronotum shape among the twelve populations of the Coconut Leaf Bettle (B. longissima, Gestro). A. All female populations only (Wilks' Lambdia: $0.4175 ; p$-value: $7.62 \times 10^{-184}$; Pillai Trace: $0.6297 ; p$-value: 2.217 $\times 10^{-157}$ ) . B. All male populations only (Wilks' Lambdia: 0.3554; $p$-value: $1.289 \times 10^{-220}$; Pillai Trace: $0.7328 ; p$-value: $\left.5.339 \times 10^{-193}\right)$. C. Combined Populations (Wilks' lambdia: 0.391; $p$-value: 0; Pillai Trace: 0.6849; $p$-value: 0 ).

Comparing the pronotum shapes of the all-female, all-male, and combined populations, CVA scatter plots were generated based on the pooled and most important relative warp scores (Fig. 5). All three scatter plots and scores revealed a randomly distributed pronotum shape, which may suggest high intrapopulation variation. However, it is important to note that results of the non-parametric Kruskal-Wallis test $\left(p=1.153^{-118}<0.05\right.$ for the all-female; $p=4.01^{-31}<0.05$ for the 
all-male; and $p=1.407^{-226}<0.05$ for the combined populations) showed that there were significant differences between the medians of two or more populations. Table III-Table V shows the result of the Bonferroni corrected Mann-Whitney pairwise comparison of the first and second relative warp scores, the two most significant, of the pronotum shape of the different Brontispa populations.

Cluster analysis of the centroid size of the pooled populations also showed the formation of two separate clusters, with one cluster consisting of almost all-male populations with the exception of one female population and the other one further clustering into two separate sub-clusters. In the first cluster, which consisted of almost entirely male populations, the male pronotum shape of Bayang, Malangas, Aloran, and Aurora populations and the female pronotum shape of Bubong populations were not significantly different with one another (Fig. 8). In the first sub-cluster of the se cond cluster group, the female Pantao Ragat population showed no significant difference towards the female Aurora and the male Marawi populations. This possibly suggested that the two populations may share a common origin with the female Pantao Ragat population. In the second sub-cluster, the female populations from Bayang, Malangas and Marawi were found to be not significantly different from each other. The Sibutad male and female populations in the sub-cluster were found to be distinct from one another.

TABLE III: Result of the KRUSKal-Wallis Test on the Pronotum Shape of the AlL-Female Populations Based on the FiRST AND SeCond RELATIVE WARP SCORE. Highlighted VALUES INDiCATE SignificANT DifFERENCE (LEVEL OF SigNificANCE =0.05)

\begin{tabular}{|c|c|c|c|c|c|c|c|c|c|c|c|c|}
\hline \multirow{2}{*}{ Locality } & \multicolumn{12}{|c|}{ Locality } \\
\hline & 1 & 2 & 3 & 4 & 5 & 6 & 7 & 8 & 9 & 10 & 11 & 12 \\
\hline 1 & - & & & & & & & & & & & \\
\hline 2 & 1 & - & & & & & & & & & & \\
\hline 3 & 1 & 1 & - & & & & & & & & & \\
\hline 4 & 1 & 1 & 1 & - & & & & & & & & \\
\hline 6 & 0.82 & 1 & 1 & 1 & $3.709^{-16}$ & - & & & & & & \\
\hline 7 & $1.317^{-12}$ & $3.794^{-12}$ & $2.111^{-10}$ & $8.636^{-18}$ & 1 & $2.02^{-09}$ & - & & & & & \\
\hline 8 & 0.6688 & 1 & 1 & 1 & $5.133^{-09}$ & 1 & $1.356^{-04}$ & - & & & & \\
\hline 9 & $5.479^{-27}$ & $1.104^{-27}$ & $3.091^{-25}$ & $2.761^{-29}$ & $3.372^{-04}$ & $1.156^{-25}$ & $1.374^{-07}$ & $1.953^{-17}$ & - & & & \\
\hline 10 & $4.726^{-19}$ & $1.651^{-19}$ & $3.204^{-17}$ & $1.455^{-21}$ & 1 & $3.234^{-17}$ & 0.355 & $8.913^{-10}$ & $1.348^{-02}$ & - & & \\
\hline 12 & $1.439^{-31}$ & $7.625^{-34}$ & $5.256^{-31}$ & $1.798^{-35}$ & $1.682^{-06}$ & $2.492^{-32}$ & $2.408^{-32}$ & $2.548^{-22}$ & 1 & $5.64^{-06}$ & $1.329^{-32}$ & - \\
\hline
\end{tabular}

Legend: 1 - Aloran-Female; 2 - Aurora-Female; 3 - Bayang-Female; 4 - Bubong-Female; 5 - Butuan City-Female; 6 - Malangas-Female; 7 - Marawi City-Female; 8 - Musuan,-Female; 9 - Pagadian City-Female; 10 - Pantao Ragat-Female; 11 - Sibutad-Female; 12 - Wao-Female.

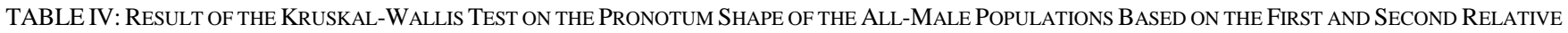
WARP SCORE. Highlighted VALUES INDICATE SigNifiCANT DiFFERENCE (LEVEL OF SigNifiCANCE $=0.05$ )

\begin{tabular}{|c|c|c|c|c|c|c|c|c|c|c|c|c|}
\hline \multirow{2}{*}{ Locality } & \multicolumn{12}{|c|}{ Locality } \\
\hline & 1 & 2 & 3 & 4 & 5 & 6 & 7 & 8 & 9 & 10 & 11 & 12 \\
\hline 1 & - & & & & & & & & & & & \\
\hline 2 & $9.892^{-03}$ & - & & & & & & & & & & \\
\hline 3 & $3.94^{-05}$ & 1 & - & & & & & & & & & \\
\hline 4 & $6.28^{-08}$ & $3.792^{-02}$ & 0.1878 & - & & & & & & & & \\
\hline 5 & 1 & 0.1053 & $8.99^{-05}$ & $7.08^{-08}$ & - & & & & & & & \\
\hline 6 & 0.1754 & 1 & 1 & $6.506^{-03}$ & 1 & - & & & & & & \\
\hline 7 & $2.399^{-03}$ & 1 & 1 & $3.337^{-02}$ & 0.0777 & 1 & - & & & & & \\
\hline 8 & 0.2283 & 1 & 0.2257 & $5.49^{-06}$ & 1 & 1 & 1 & - & & & & \\
\hline 9 & 1 & $3.18^{-03}$ & $7.43^{-06}$ & $1.66^{-07}$ & 1 & $6.771^{-02}$ & $3.66^{-04}$ & $2.995^{-02}$ & - & & & \\
\hline 10 & 1 & $3.879^{-03}$ & $2.10^{-06}$ & $1.01^{-08}$ & 1 & 0.1587 & $6.98^{-04}$ & 0.06579 & 1 & - & & \\
\hline 11 & 1 & $2.56^{-06}$ & $2.18^{-10}$ & $1.02^{-13}$ & 0.4719 & $5.96^{-04}$ & $1.18^{-06}$ & $2.14^{-04}$ & 1 & 1 & - & \\
\hline
\end{tabular}

Legend: 1 - Aloran-Male; 2 - Aurora- Male; 3 - Bayang- Male; 4 - Bubong-Male; 5 - Butuan City- Male; 6 - Malangas- Male; 7 - Marawi City- Male; 8 - Musuan,- Male; 9 - Pagadian City- Male; 10 - Pantao Ragat- Male; 11 - Sibutad- Male; 12 - Wao- Male.

Shape variability in these populations can be attributed to several factors, which could either be genetic, environmental or behavioral. It has been suggested that morphological variation may be influenced by physiological (or pathological) status, adaptive changes or genetic differences [21]. Several hypotheses could be used to possibly explain the shape variation. Climate change has been suggested to possibly play a role in causing variability on insect pest dynamics, in which the seasonal effects of weather and the ongoing changes in climatic condition will lead directly to modification to dispersal and development of insect pest. This change would certainly involve alteration in developmental rates, voltinism and survival of insects and subsequently act upon size, density and genetic composition of populations, as well as host plant exploitation [22]. The host plant in the sampling site may also play a role in the variation. Induced 
plant responses were reported to produce variations in terms of their nutritional status, secondary substances and physical characteristics [4]. Another possible reason could be wind dispersal in close geographical locations. Dispersal, a vital aspect of zoogeography, is of prime importance if the insect is to succeed. Increase of mean distance between neighboring individuals was a phenomenon common to all organisms [23]. Other studies also reported that there are evidences to show that temperature, adverse nutritional stress, chemical presence, population density and many other factors causing stress during development can lead to increasing fluctuating asymmetry [24], to which altering the insect's environmental conditions would drive the organism and its population to adapt to new conditions, which in turn would lead to the dampening of the symmetric phenotype in response to the disturbances that occur during morphogenesis.

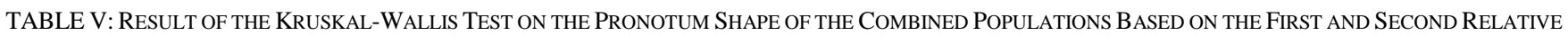
WARP SCORE. Highlighted VALUES INDICATE SigNIFICANT DifFERENCE (LEVEL OF SigNIFICANCE $=0.05$ )

\begin{tabular}{|c|c|c|c|c|c|c|c|c|c|c|c|c|c|}
\hline \multirow{2}{*}{ Locality } & \multicolumn{13}{|c|}{ Locality } \\
\hline & 1 & 2 & 3 & 4 & 5 & 6 & 7 & 8 & 9 & 10 & 11 & 12 & 13 \\
\hline 1 & - & & & & & & & & & & & & \\
\hline 2 & 1 & - & & & & & & & & & & & \\
\hline 3 & 1 & 1 & - & & & & & & & & & & \\
\hline 4 & 1 & 1 & 1 & - & & & & & & & & & \\
\hline 5 & $8.94^{-18}$ & $1.16^{-17}$ & $3.94^{-17}$ & $3.11^{-20}$ & - & & & & & & & & \\
\hline 6 & 1 & 1 & 1 & 1 & $7.83^{-15}$ & - & & & & & & & \\
\hline 7 & $3.62^{-12}$ & $8.03^{-12}$ & $3.04^{-11}$ & $2.87^{-13}$ & 1 & $4.96^{-09}$ & - & & & & & & \\
\hline 8 & 1 & 1 & 1 & 1 & $7.5^{-10}$ & 1 & $2.66^{-05}$ & - & & & & & \\
\hline 9 & $3.53^{-30}$ & $1.15^{-31}$ & $1.08^{-30}$ & $5.65^{-35}$ & $2.97^{-04}$ & $4.26^{-30}$ & $2.01^{-09}$ & $3.16^{-21}$ & - & & & & \\
\hline 10 & $1.54^{-17}$ & $1.06^{-17}$ & $7.38^{-17}$ & $2.14^{-20}$ & 1 & $1.91^{-15}$ & 1 & $3.25^{-09}$ & $1.06^{-04}$ & - & & & \\
\hline 11 & 1 & 1 & 1 & 1 & $6.11^{-16}$ & 1 & $1.79^{-10}$ & 1 & $1.90^{-29}$ & $4.36^{-16}$ & - & & \\
\hline 12 & $3^{-31}$ & $2.57^{-33}$ & $1.72^{-31}$ & $1.76^{-35}$ & $1.49^{-05}$ & $8.64^{-31}$ & $4.71^{-11}$ & $1.65^{-22}$ & 1 & $1.26^{-06}$ & $4.68^{-31}$ & - & \\
\hline 13 & 1 & 1 & $6.85^{-02}$ & $5.08^{-02}$ & $2.80^{-26}$ & $3.46^{-04}$ & $3.04^{-20}$ & $3.94^{-03}$ & $4.62^{-38}$ & $8.09^{-26}$ & 1 & $1.63^{-38}$ & - \\
\hline 14 & $5.88^{-1}$ & 1 & 1 & 1 & $1.71^{-08}$ & 1 & $5.16^{-04}$ & 1 & $7.46^{-21}$ & $2.10^{-08}$ & 1 & $2.59^{-22}$ & $4.04^{-05}$ \\
\hline 15 & 1 & 1 & 1 & 1 & $1.88^{-12}$ & 1 & $5.06^{-07}$ & 1 & $2.39^{-26}$ & $2.30^{-12}$ & 1 & $2^{-27}$ & $9.40^{-05}$ \\
\hline 16 & 1 & 1 & 1 & 1 & $1.70^{-08}$ & 1 & $7.83^{-05}$ & 1 & $2.21^{-18}$ & $4.77^{-08}$ & 1 & $7.57^{-20}$ & $4.2^{-01}$ \\
\hline 17 & $9.38^{-16}$ & $9.43^{-16}$ & $4.74^{-15}$ & $1.46^{-17}$ & 1 & $1.14^{-12}$ & 1 & $1.05^{-08}$ & $4.69^{-04}$ & 1 & $3.85^{-14}$ & $4.33^{-05}$ & $1.15^{-23}$ \\
\hline 18 & $9.52^{-1}$ & 1 & 1 & 1 & $8.78^{-07}$ & 1 & $6.03^{-04}$ & 1 & $3.25^{-17}$ & $3.01^{-06}$ & 1 & $2.05^{-18}$ & $1.52^{-04}$ \\
\hline 19 & $4.72^{-10}$ & $1.19^{-09}$ & $1.60^{-08}$ & $4.96^{-10}$ & 1 & $2.39^{-06}$ & 1 & $2.77^{-04}$ & $1.76^{-07}$ & 1 & $3.62^{-09}$ & $6.80^{-09}$ & $3.29^{-17}$ \\
\hline 20 & $4.98^{-06}$ & $1.12^{-05}$ & $1.36^{-04}$ & $8.32^{-06}$ & $1.01^{-02}$ & $1.94^{-02}$ & 1 & $2.33^{-01}$ & $8.50^{-15}$ & $6.68^{-03}$ & $3.07^{-05}$ & $2.74^{-16}$ & $8.51^{-13}$ \\
\hline 21 & $1.67^{-37}$ & $5.20^{-39}$ & $1.05^{-37}$ & $5.62^{-42}$ & $4.49^{-12}$ & $6.35^{-37}$ & $1.16^{-18}$ & $1.05^{-29}$ & $1.33^{-01}$ & $1.02^{-13}$ & $3.12^{-37}$ & $6.11^{-01}$ & $1.05^{-43}$ \\
\hline 22 & $2.12^{-30}$ & $4.20^{-32}$ & $9.19^{-31}$ & $7.28^{-35}$ & $2.4^{-04}$ & $8.80^{-30}$ & $1.13^{-09}$ & $1.79^{-21}$ & 1 & $4.03^{-05}$ & $6.75^{-30}$ & 1 & $3.27^{-38}$ \\
\hline 23 & 1 & 1 & 1 & 1 & $1.57^{-13}$ & 1 & $1.90^{-08}$ & 1 & $2.64^{-26}$ & $1.97^{-13}$ & 1 & $6.74^{-28}$ & 1 \\
\hline \multirow[t]{2}{*}{24} & $1.18^{-14}$ & $1.09^{-14}$ & $3.01^{-13}$ & $1.88^{-15}$ & 1 & $1.06^{-10}$ & 1 & $1.18^{-07}$ & $3.57^{-04}$ & 1 & $1.44^{-13}$ & $1.44^{-13}$ & $4.03^{-22}$ \\
\hline & 14 & 15 & 16 & 17 & 18 & 19 & 20 & 21 & 22 & 23 & 24 & & \\
\hline 14 & - & & & & & & & & & & & & \\
\hline 15 & 1 & - & & & & & & & & & & & \\
\hline 16 & 1 & 1 & - & & & & & & & & & & \\
\hline 17 & $2.11^{-07}$ & $1.34^{-10}$ & $5.15^{-08}$ & - & & & & & & & & & \\
\hline 18 & 1 & 1 & 1 & $6.97^{-06}$ & - & & & & & & & & \\
\hline 19 & $4.56^{-03}$ & $6.06^{-05}$ & $1.78^{-04}$ & 1 & $2.4^{-02}$ & - & & & & & & & \\
\hline 20 & 1 & $1.19^{-01}$ & $9.41^{-02}$ & $2.24^{-02}$ & 1 & 1 & - & & & & & & \\
\hline 21 & $1.73^{-29}$ & $4.02^{-34}$ & $8.56^{-26}$ & $1.87^{-11}$ & $3.33^{-25}$ & $1.97^{-15}$ & $1.97^{-23}$ & - & & & - & & \\
\hline 22 & $3.35^{-21}$ & $2.75^{-26}$ & $7.79^{-19}$ & $4.28^{-04}$ & $1.67^{-17}$ & $1.18^{-07}$ & $6.46^{-15}$ & 0.102 & - & & & & \\
\hline 23 & 1 & 1 & 1 & $4.38^{-12}$ & 1 & $3.69-07$ & $1.32^{-03}$ & $1.40^{-34}$ & $1.05^{-26}$ & - & & & \\
\hline 24 & $4.71^{-06}$ & $4.71^{-09}$ & $1.36^{-07}$ & 1 & $6.56^{-05}$ & 1 & $8.39^{-02}$ & $2.66^{-12}$ & $2.06^{-4}$ & $2.11^{-11}$ & - & & \\
\hline
\end{tabular}

Legend: 1 - Aloran-Female; 2 - Aurora-Female; 3 - Bayang-Female; 4 - Bubong-Female; 5 - Butuan City-Female; 6 - Malangas-Female; 7 - Marawi City-Female; 8 - Musuan,-Female; 9 - Pagadian City-Female; 10 - Pantao Ragat-Female; 11 - Sibutad-Female; 12 - Wao-Female; 13 - Aloran-Male; 14 Aurora-Male; 15 - Bayang-Male; 16 - Bubong-Male; 17 - Butuan City-Male; 18 - Malangas-Male; 19 - Marawi City-Male; 20 - Musuan-Male; 21 Pagadian City-Male; 22 - Pantao Ragat-Male; 23 - Sibutad-Male; 24 - Wao-Male. 


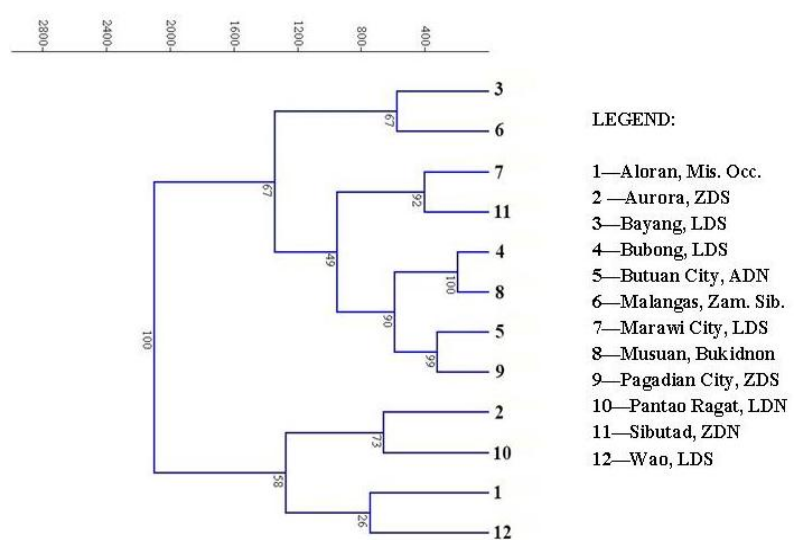

Fig. 6. Cluster analysis result of the different pronotum shape based on the centroid size of the all-female populations only.

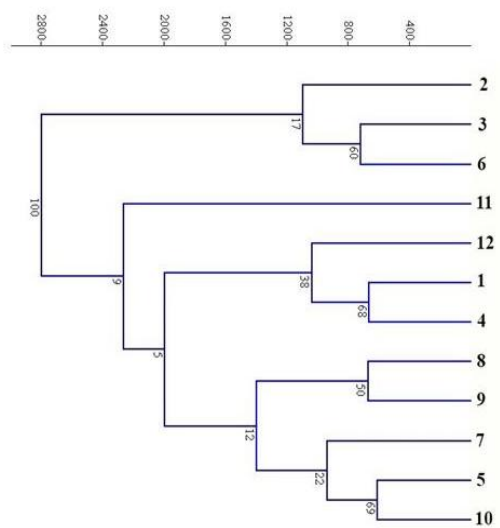

Fig. 7. Cluster analysis result of the different pronotum shape based on the centroid size of the all-male populations only.
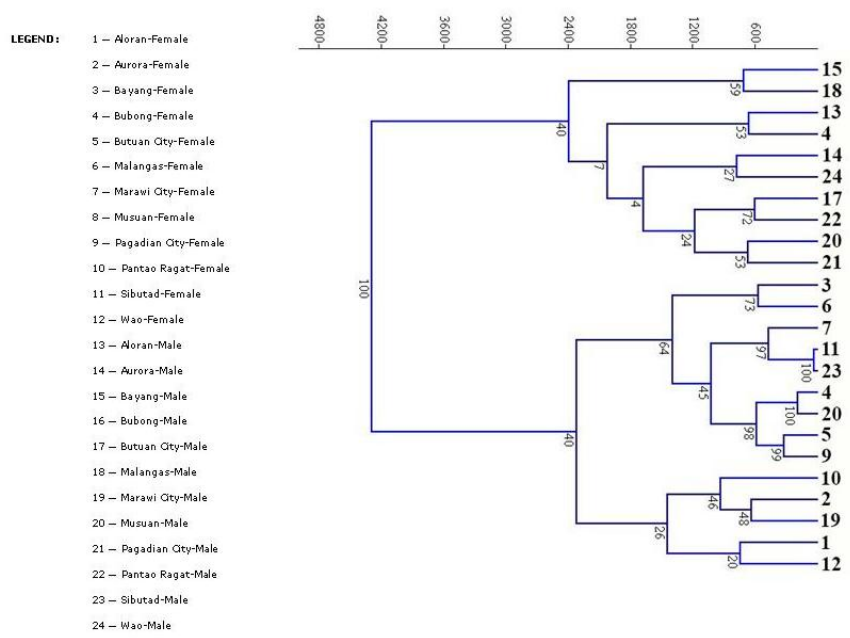

Fig. 8. Cluster analysis result of the different pronotum shape based on the centroid size for the combined twelve populations of B. longissima.

\section{CONCLUSION}

The result of the study showed that there is a significant relationship in the Brontispa longissima pronotum shape with regards to its shape variability. The results suggest the existence of morphological differences in the populations of the insect which in turn may help lead into the uncovering of the environmental factors or genetic differentiation of the population structure. It is highly recommended that more genetic and behavioral studies on the insect pest be conducted to further determine the specific intra- or interpopulation causes of variability of the pronotum.

\section{ACKNOWLEDGMENT}

The authors would like to thank Prof. Muhmin Michael M. Manting for providing the landmarks used in the study; Ms. Christine Lovelle A. Mahinay and Jade Marie M. Sobrepeña for the technical assistance in the statistical proper of the samples; Jomari M. Sobrepeña for the aid in the landmarking proper of the study; and the Department of Science and Technology for the funding support of the study.

\section{REFERENCES}

[1] W. Liebergts and K. Chapman, "Impact and control of the coconut hispine beetle, Brontispa Longissima gestro (Coleoptera: Chrysomelidae)," presented at the Report of the Expert Consultation on Coconut Beetle Outbreak in APPPC Member Countries, Bangkok, Thailand, October 26-27, 2004.

[2] L. S. He, K. H. Ong, C. P. Yik, Y. K. Fong, and H. J. A. Chan, "Chemical control of hispid beetles (Brontispa Longissima) on Palms," Singapore J. Pird Ind., vol. 32, pp. 80-92, 2005.

[3] S. Ayri and V. V. Ramamurthy, "Diagnostics of coconut leaf beetle Brontispa Longissima (Gestro) and its importance as an invasive species," Mun. Ent. Zool., vol. 7, no. 2, pp. 787-791, June 2012.

[4] S. R. M. Tabugo, M. A. J. Torres, L. F. Olowa, M. A. B. Sabaduquia, R. M. Macapil, A. M. Acevedo, and C. G. Demayo, "Elliptic fourier analysis in describing shape of mandible of the larvae of the coconut leaf beetle Brontispa Longissima Gestro, 1885 (Chrysomelidae: Hispinae) collected from plants with varying degrees of damage," International Research Journal of Biological Sciences, vol. 1, no. 8, pp. 19-26, December 2012.

[5] D. Gotzek, S. G. Brady, R. J. Kallal, and J. S. LaPolla, "The importance of using multiple approaches for identifying emerging species: The case of the raspberry crazy ant in the United States," PLOS ONE, vol. 7, no. 9, pp. 1-10, September 2012.

[6] M. A. J. Torres, C. G. Demayo, A. T. Barrion, L. S. Sebastian, and A. D. Barrion, "Relative warps analysis of shape variability of the head and pronotum in selected populations of the rice black bug," Australian Journal of Basic and Applied Science, vol. 4, no. 10, pp. 4655-4670, October 2010.

[7] H. Iwata and Y. Ukai, "Shape: A computer program package for quantitative evaluation of biological shapes based on elliptic Fourier descriptors," The Journal of Heredity, vol. 93, no. 5, pp. 384-385, August 2002.

[8] A. Yamashita and K. Takasu, "Sustainability of potential host plant in Japan for immature development of the coconut hispine beetle, Brontispa Longissima (Gestro) (Coleoptera: Chrysomelidae)," JARQ, vol. 44, no. 2, pp. 143-149, May 2009.

[9] A. Yamashita, A. Winotai, and K. Takasu, "Use of mature leaves of coconut palm and narrowleaf cattail for laboratory rearing of the coconut leaf beetle Brontispa longissima," Bull. Inst. Trop. Agr., Kyushu Univ, vol. 31, pp. 61-67, 2008.

[10] N. T. Loc et al., "Biocontrol potential of Metarhizium Anisopliae against coconut beetle, Brontispa Longissima," Omonrice, vol. 12, pp. 85-91, 2004

[11] L. Chaojun, B. Zhong, G. Zhong, Q. Weng, S. Chen, M. Hu, X. Sun, and W. Qin, "Four botanical extracts are toxic to the hispine beetle, brontispa longissima, in laboratory and semi-field trials," Journal of Insect Science, vol. 12, no. 58, pp. 1-8, January 2011.

[12] P. Rethinam and S. P. Singh, "Current status of the coconut beetle outbreaks in the Asia-Pacific region," in Proc. from the Report of the Asia-Pacific Forest Invasive Species Network Workshop, ho Chi Minh City, Vietnam, February 22-25, 2005.

[13] C. L. Ma, H. L. Wu, H. Y. Hu, X. Wu, G. C. Ma, Y. G. Fu, and Z. Q. Peng, "Isolation and characterization of eight polymorphic microsatellite loci for the coconut pest, Brontispa Longissima (Coleoptera: Hispidae)," Genetics and Molecular Research, vol. 10, no. 1, pp. 429-432, March 2011.

[14] F. J. Rohlf, tps Utility Program Version 1.44, New York: Department of Ecology and Evolution, State University of New York at Stony Brook, 2009.

[15] L. M. L. D. Cruz, M. A. J. Torres, A. T. Barrion, R. Joshi, L. S. Sebastian, and C. G. Demayo, "Geometric morphometric analysis of the head, pronotum, and genitalia of the rice black bug associated with 
selected rice types," Egypt. Acad. J. Biolog. Sci, vol. 4, no. 1, pp. 21-31, February 2011.

[16] F. J. Rohlf, Tps Dig Version 2.12, New York: Department of Ecology and Evolution, State University of New York at Stony Brook, 2008.

[17] F. J. Rohlf, Tps Util Version 1.46, New York: Department of Ecology and Evolution, State University of New York at Stony Brook, 2008.

[18] N. G. M. Z. Khiaban, K. H. I. Nejad, M. S. Hejazi, S. A. Mohammadi, and N. Sokhandan, "A geometric morphometric study on the host population of the pod borer, Helicoverpa Armigera (Hübner) (Lepidoptera: Noctuidae) in Some Parts of Iran," Mun. Ent. Zool., vol. 5, no. 1, pp. 140-147, January 2010.

[19] Ø. Hammer, D. A. T. Harper, and P. D. Ryan, "PAST: Paleontological statistics software package for education and data analysis," Paleontological Electronica, vol. 4, no. 1, pp. 1-9, June 2001.

[20] J. M. M. Sobrepeña and C. G. Demayo, "banding pattern and shape morphology variations on shells of the invasive giant African land snail Achatina Fulica (Bowdich 1822) from the Philippines," Annals of Biological Research, vol. 5, no. 1, pp. 64-79.

[21] J. P. Duranjin and D. E. Slice, "Contributions of morphometrics to medical entomology," Encyclopedia of Infectious Diseases: Modern Methodologies, New Jersey, USA: John Wiley and Sons, Inc., 2007, pp 433-446.

[22] V. Karuppaiah and G. K. Sujayanad, "Impacts of climate change on population dynamics on insect pests," World Journal of Agricultural Sciences, vol. 8, no. 3, pp. 240-246, 2012.

[23] E. P. Holzapfel and J. C. Harrell, "Transoceanic dispersal studies on insect," Pacific Insects, vol. 10, no. 1, pp.115-153, May 1968.
[24] H. A. Benitez, R. Briones, and V. Jerez, "Intra and inter-population morphological variation of shape and size of the Chilean magnificent beetle, Ceroglossus chilensis in the Baker River Basin, Chilean Patagonia," Journal of Insect Science, vol. 11, no. 94, pp. 1-9, May 2011.

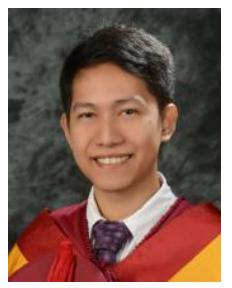

Kris A. Ortizo is currently pursuing his degree in master of science in biology at Mindanao State University, - Iligan Institute of Technology, Iligan City, Philippines.

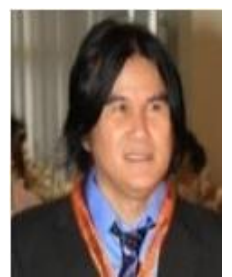

Cesar G. Demayo is currently a professor and the chairman of the Department of Biological Sciences, College of Science and Mathematics, MSU-Iligan Institute of Technology, Iligan City, Philippines. His researches include environmental toxicology, biodiversity and genetics. He is an active member of the Philippine Society for the Study of Nature and the Pest Management Council of the Philippines. 